\title{
Quality evaluation of diamond wire-sawn gallium-doped silicon wafers
}

\author{
Kyoung Hee Lee ${ }^{\dagger}$ \\ Department of Biochemical Engineering, Dongyang Mirae University, Seoul 152-714, Korea \\ (Received March 14, 2013) \\ (Revised April 12, 2013) \\ (Accepted April 19, 2013)
}

\begin{abstract}
Most of the world's solar cells in photovoltaic industry are currently fabricated using crystalline silicon. Czochralski-grown silicon crystals are more expensive than multicrystalline silicon crystals. The future of solar-grade Czochralski-grown silicon crystals crucially depends on whether it is usable for the mass-production of high-efficiency solar cells or not. It is generally believed that the main obstacle for making solar-grade Czochralski-grown silicon crystals a perfect high-efficiency solar cell material is presently light-induced degradation problem. In this work, the substitution of boron with gallium in p-type silicon single crystal is studied as an alternative to reduce the extent of lifetime degradation. The diamond-wire sawing technology is employed to slice the silicon ingot. In this paper, the quality of the diamond wiresawn gallium-doped silicon wafers is studied from the chemical, electrical and structural points of view. It is found that the characteristic of gallium-doped silicon wafers including texturing behavior and surface metallic impurities are same as that of conventional boron-doped Czochralski crystals.
\end{abstract}

Key words Silicon, Czochralski, Diamond wire saw, Gallium doping, Quality evaluation

\section{Introduction}

Most of the present world solar cell production is based on boron-doped crystalline silicon, with Czochralski-grown single crystalline silicon and cast multicrystalline silicon. In spite of its complicated manufacture and high cost, crystalline silicon still dominates the market today and will probably continue to do so in the immediate future. This is mostly due to the fact that there is an abundant supply of silicon as a raw material, high efficiencies are feasible, the ecological impact is low and silicon in its crystalline form shows practically no degradation with time [1].

It is known that high efficiency solar cells made of Czochralski-grown single crystalline silicon undergo a moderate decrease in efficiency when exposed to light [2-6]. Despite the fact that the efficiencies obtained on Czochralski-grown single crystalline silicon are initially much higher compared to those attained on the cheaper cast multicrystalline silicon materials, efficiencies closely approach after a few hours of illumination. This is due to the fact that multicrystalline silicon solar cells are, in most cases, stable under illumination. Since, in general, Czochralski-grown single crystalline silicon is more

\footnotetext{
Corresponding author

Tel: +82-2-2610-1813

Fax: +82-2-2610-1858

E-mail: 1kh@dongyang.ac.kr
}

expensive than multicrystalline silicon, the future of solargrade Czochralski-grown single crystalline silicon crucially depends on whether it is usable for the mass-production of high-efficiency solar cells or not. Hence, in recent years, a lot of research has been devoted to the light-induced degradation (LID) problem, which is presently the main obstacle for making solar-grade Czochralski-grown single crystalline silicon a perfect highefficiency solar cell material. It is also known that a floating zone material does not show this behavior, however, for economic reasons, only Czochralski crystals are used in production. Recently, the reasons for the degradation of efficiency have been determined and ways have been found to prevent it [7]. These observations justify the hypothesis that boron and oxygen are the major components of the metastable defect underlying Czochralski-specific lifetime degradation. The suppression of Czochralski-specific lifetime degradation can easily lead to an absolute efficiency improvement by several percent. This Czochralski-grown silicon specific lifetime degradation is induced by carrier injection or illumination. In principle, three different means of suppressing lifetime degradation can be distinguished. Alternatives for reducing the extent of lifetime degradation are the use of materials with very low concentrations or free of oxygen, such as magnetic Czochralskigrown silicon or floating zone grown silicon, the use of n-type Czochralski silicon and the substitution of boron 
with gallium in p-type Czochralski silicon.

The high-cost of crystalline silicon material causes a barrier for the world wide application of solar cells [8]. One strategy is to reduce the thickness of silicon wafers $[9,10]$, which is strongly dependent on the sawing technology. The wire sawing is now popularly used in the wafering process. It is often carried out by a steel wire transporting abrasive slurry, which proceeds by abrasive silicon-carbide ( $\mathrm{SiC}$ ) particles being squeezed between the wire and the silicon ingot. This technology can yield a large productivity, but unavoidably has the environmental impacts of slurries and chemicals used to clean the wafer surfaces after slicing. Meanwhile, this technology has a big disadvantage of silicon swarf that contains fine $\mathrm{SiC}$ particles mixed with silicon powder and other organic coolants. Recycling the silicon swarf by removing $\mathrm{SiC}$ particles has not yet been successfully reported so far. The reason is that the $\mathrm{SiC}$ particles cannot be filtered or separated by centrifuges. Furthermore, the slurry wire sawing technology usually causes large surface damage. This necessarily results in a huge breakage of wafers, especially for the thin wafers. Therefore, novel techniques are needed to cut thin wafers from a silicon ingot with reduced breakage. An alternative to the slurry-wire sawing technology is emerging in the form of diamond-plated wire sawing. The wire is coated by diamond particles by electrical plating and the abrasive slurry is replaced by a cooling liquid. It provides a high potential for the thinner wafer slicing using thinner wires and higher possibilities of recycling the silicon swarf due to the absence of $\mathrm{SiC}$ particles. In addition, diamond-wire slicing will reduce the usage of oil based slurries and wafer cleaning chemicals and will bring a new horizon for cheap silicon based solar cells. In this work, we have employed the diamond-wire sawing technology to slice the silicon ingot. The surface damage and mechanical properties of the wafers have been investigated as compared to slurry-wire sawn wafers [11].

In this paper, the substitution of boron with gallium in p-type Czochralski-grown silicon ingots was studied by the quality evaluation for the diamond wire-sawn wafers.

\section{Experimental Procedure}

Czochralski silicon crystals with a diameter of $200 \mathrm{~mm}$ and a length of 2,000 mm were grown using 24 inch hot zone configuration to evaluate the quality of Czochralskigrown silicon single crystals using conventional boron and gallium doping method. The most important three steps in conventional Czochralski crystal growth are melting polysilicon, seeding, and growing. Doping Czochralski-grown silicon crystals with gallium offers a sure way of eliminating the LID problem because the LID defect is composed of boron and oxygen complex. The detailed Czochralski silicon growth steps for gallium doping were explained by Hoshikawa et al. [12].

\section{Results and Discussion}

In this study, (100)-oriented $200 \mathrm{~mm}$ diameter crystals were grown by Czochralski method. B-doped and Gadoped ingots were sliced to wafers using diamond wire sawing technology to study the possibility of using Gadoped Czochralski ingots for photovoltaic application.

\subsection{Electrical Characterization}

The importance of silicon in the electronic device technology relies on semi-conducting properties, which can be controlled by small addition of impurity element, that is, dopants, such as group III element (e.g., boron, gallium) for acceptors and group V elements (e.g., phosphorus) for donor. The dopant impurities play a key role in semiconductor device operation. Impurity atoms with $\mathrm{K}$ (equilibrium segregation coefficient) $<1$ are rejected by the advancing solid at a greater rate than they can diffuse into the bulk of the melt. Most values for the commonly used dopants for silicon are below 1, which denotes that during growth the dopants are rejected into the melt. In melt crystal growth process, with the start of solidification at a given crystal-melt interface, segregation takes place and the rejected impurity atoms begin to accumulate in the melt layer near the growth interface and diffuse in the direction of the bulk of the melt. An impurity concentration gradient develops ahead of advancing crystal.

The experimental and analytical axial resistivity distribution in conventional and codoping process was shown by Lee [1]. The low segregation coefficient of gallium (Ga) in silicon melt causes a much wider resistivity variation as a function of crystal length. The segregation coefficient of $\mathrm{B}$ is large, 0.8 and that of $\mathrm{Ga}$ is very small, 0.008. There is very little evaporation of B atoms from the silicon melt during the crystal growth. The evaporation rate of $\mathrm{Ga}$ from the silicon melt is considerably greater than that of $\mathrm{B}$, however, the detailed evaporation behavior of $\mathrm{Ga}$ in Czchralski growth of silicon crystal is poorly known $[1,12]$. Because of resistivity 


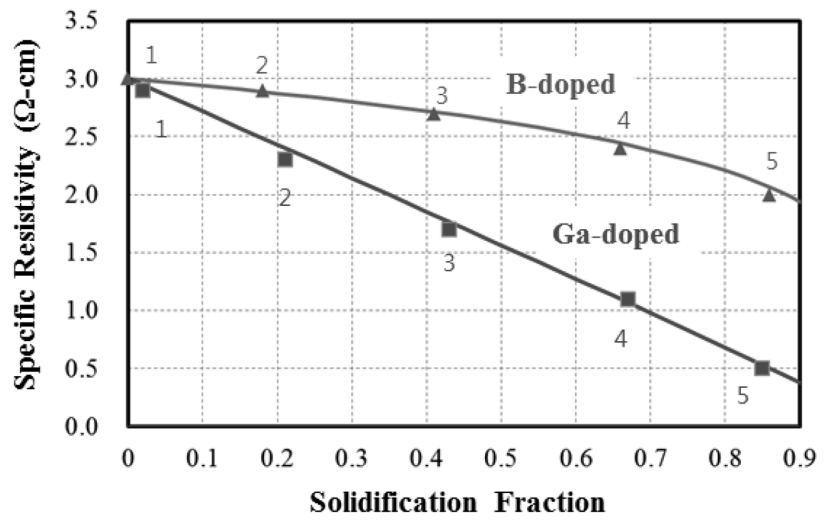

Fig. 1. The predicted resistivity distribution as a function of fraction solidified and the position of wafers.

variation along the crystal length, the silicon wafers from different positions along the axial direction of grown crystals were studied. Ga- and B-doped ingots were grown as the seed target resistivity of $3 \mathrm{ohm}-\mathrm{cm}$. The predicted resistivity distribution and the positions of wafers in the ingots are shown in Fig. 1.

The bulk minority carrier lifetime (MCLT) was studied for both crystals by noncontact photo-conductance measurement. A light-soaked measurement was performed after light-soaking for more than 24 hours to get the stabilized lifetimes after LID. The surface of samples was passivated by an iodine/methanol solution during the lifetime measurement. In this study, the wafers of position-1 and position-5 were not used to eliminate the effect of [Oi] and metallic impurities on the electrical characteristic.

The bulk MCLT of as-grown and after light-soaking samples for B- and Ga-doped wafers for different positions of Czochralski-grown ingots are shown in Fig. 2. The B-doped ingot showed a tight distribution of MCLT. Unlike the samples of B-doped crystal, the samples of Ga-doped ingot did not show any LID. The lifetime is

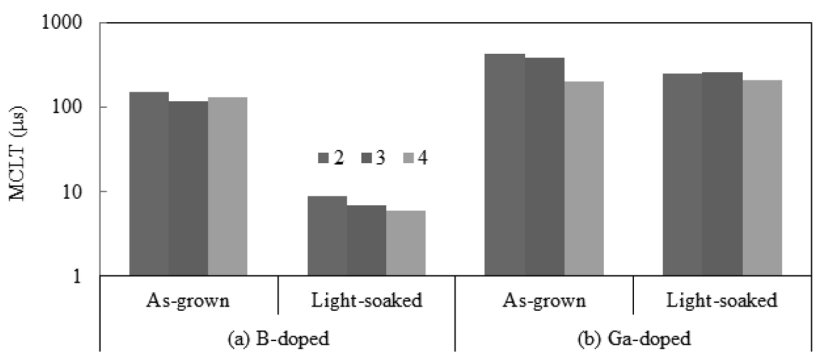

Fig. 2. Bulk minority carrier lifetime of as-grown and after light-soaking samples for (a) B-doped and (b) Ga-doped wafers for different positions of Czochralski-grown ingots.

decreased from the seed to the tail position.

\subsection{Physical Characterization}

The diamond wire sawing of silicon bricks emerges as a serious alternative to the so far established multi-wire $\mathrm{SiC}$ slurry sawing process. The diamond wire process has numerous advantages, such as a higher productivity, a lower wear of the wire, and an easier recycling of the cooling liquid. However, both sawing processes lead to very different surface structures. Already the visual inspection of the two wafer types reveals their differences. The slurry sawing wafers have a regular grey appearance in contrast to the diamond wire-sawn wafers with a silver shiny surface and clearly visible parallel grooves.

The SEM micrographs in Fig. 3 show (a) B-doped and (b) Ga-doped diamond wire-sawn silicon single crystalline wafer surfaces. The diamond wire sawn wafer features smooth parts, parallel rifts, individual fractures, and areas of cracks along the rifts. The surface roughness of (a) B-doped and (b) Ga-doped diamond wiresawn silicon single crystalline wafer are shown together

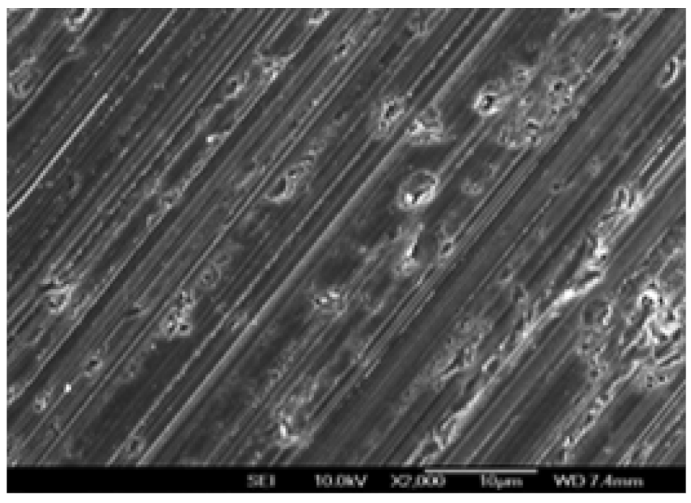

(a)

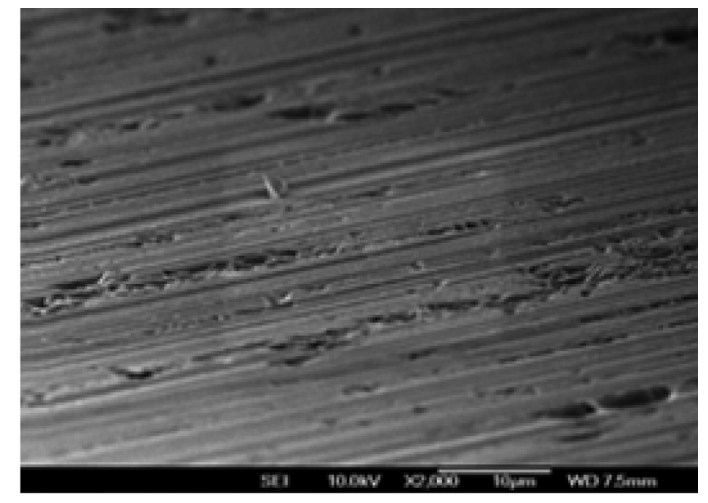

(b)

Fig. 3. SEM micrographs of (a) B-doped and (b) Ga-doped diamond wire-sawn silicon single crystalline wafer surfaces. 


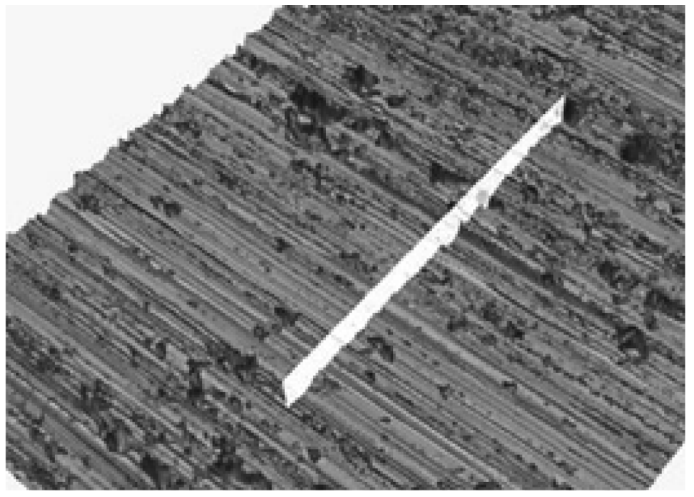

(a)

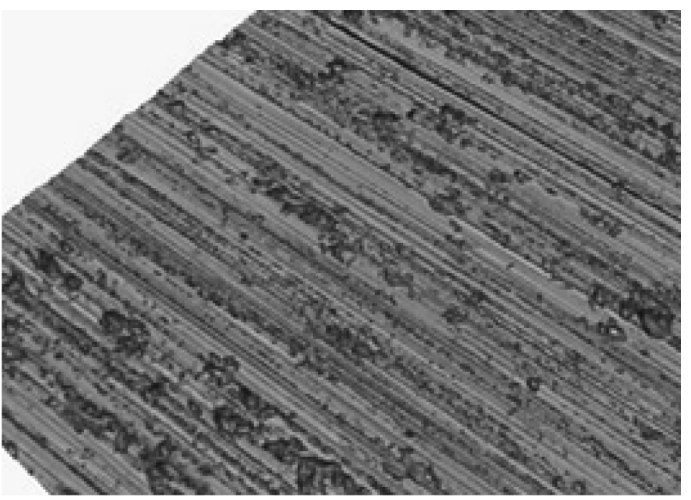

(b)

Fig. 4. Surface roughness of (a) B-doped $(\mathrm{Ra}=0.158 \mu \mathrm{m})$ and $(\mathrm{b})$ Ga-doped $(\mathrm{Ra}=0.160 \mu \mathrm{m})$ diamond wire-sawn silicon single crystalline wafer.

in Fig. 4. The initial reflectance of the diamond wiresawn wafers is typically higher than that of the slurry processing wafers. These smooth regions of the diamond wire-sawn wafer might be considered as the reason for the higher reflectivity values for the diamond wire-sawn wafer. From the point of view of the as-cut surface and the surface roughness, the physical characteristic of silicon single crystals grown by Czochralski using Ga-doping is similar to that of conventional B-doped Czochralski crystals.

\subsection{Chemical Characterization}

As the refractive index of silicon is very high, reflection at the surface of solar cells has to be minimized. Consequently, all solar cells manufactured today have an anti-reflective coating consisting of a transparent film of low refractive index. Even more efficient is surface texturing which not only reduces reflection but also provides oblique coupling of light into the cell. In this man- ner, the radiation paths are increased and enhanced absorption of infrared radiation results and conventional wet chemical texturing process can only be applied. The (100) surfaces are treated with an anisotropic etch which creates inverted pyramids bounded by (111) planes. Monocrystalline (100) silicon wafers with around $200 \mu \mathrm{m}$ thickness were etched. After etching the wafer were rinsed in water and dried. SEM pictures were taken. The SEM micrographs in Fig. 5 show the textured surface of (a) B-doped and (b) Ga-doped diamond wire-sawn silicon single crystalline wafer.

The metal impurities in specific regions at near surface of silicon wafer were determined by constant depth etching [13]. It is possible to etch uniformly over the entire wafer surface with etching solution made up of $\mathrm{HF}$ and $\mathrm{HNO}_{3}$. The solution was evaporated after etching. After spiking, the recovery of the metal impurities were found to be $90 \sim 110 \%$. In Fig. 6, the concentration of surface metallic impurities for slurry wire-sawn and diamond wire-sawn wafers measured by ICP-MS

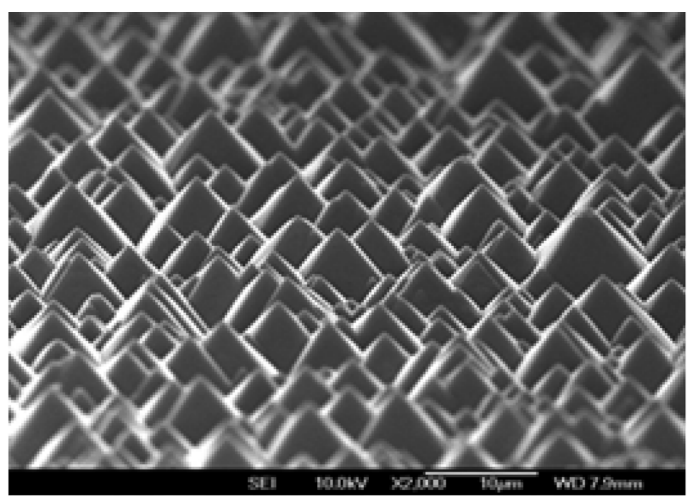

(a)

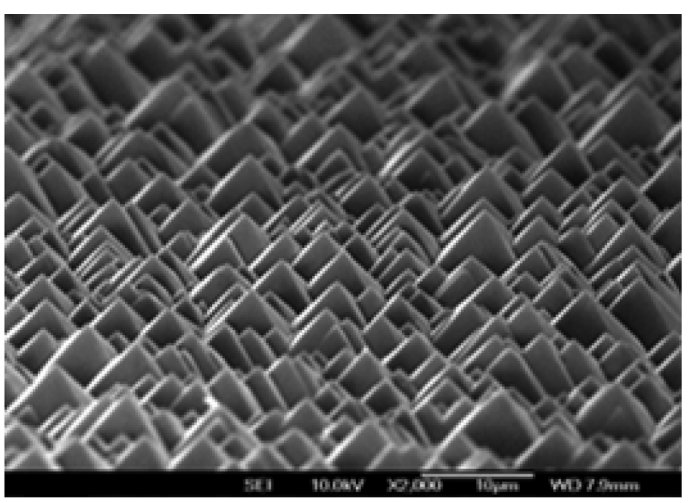

(b)

Fig. 5. SEM micrographs of the textured surface of (a) B-doped and (b) Ga-doped diamond wire-sawn silicon single crystalline wafer. 


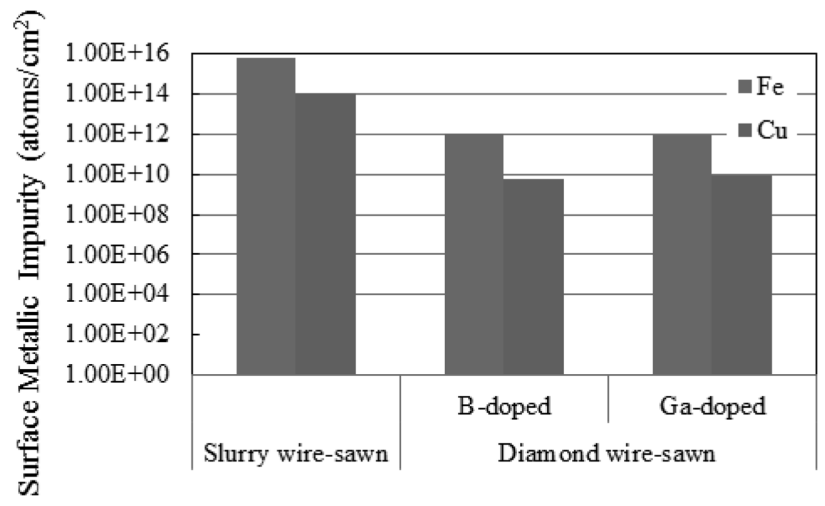

Fig. 6. Concentration of surface metallic impurities for slurry wire-sawn and diamond wire-sawn wafers. The concentration of surface metallic impurities for B-doped and Ga-doped diamond wire-sawn silicon single crystalline wafer are shown together.

are shown. The etching method was used as sample pretreatment method. The concentration of surface metallic impurities for B-doped and Ga-doped diamond wiresawn silicon single crystalline wafer are shown together. The characteristic of silicon single crystals with a diameter $200 \mathrm{~mm}$, grown by Czochralski using Ga-doping is same as that of conventional B-doped Czochralski crystals in terms of the texturing behavior and the concentration of surface metallic impurities.

\section{Conclusion}

The future of solar-grade Czochralski-grown silicon crystals crucially depends on whether it is usable for the mass-production of high-efficiency solar cells or not. It is generally believed that the main obstacle for making solar-grade Czochralski-grown silicon crystals that is a perfect high-efficiency solar cell material is presently LID problem. In this paper, the substitution of boron with gallium in p-type Czochralski silicon was studied as an alternative to reduce the extent of lifetime degradation through the quality evaluation for the diamond wire-sawn wafers. The characteristic of silicon single crystals with a diameter $200 \mathrm{~mm}$, grown by Czochralski using Gadoping including the texturing behavior and the surface roughness is the same as that of conventional B-doped Czochralski crystals. This is very important for the device fabrication process, since it is not necessary to change the thermal process and the chemical etching process for the use of Ga-doped wafers. Therefore, it is believed that p-type silicon materials grown by Czochralski crystal growth process using the Ga-doping can be used for the solar cell fabrication in the same way as the conventional wafers.

\section{Acknowledgment}

This work was supported by the research support program of the Dongyang Mirae University in 2011.

\section{References}

[1] K.H. Lee, "Axial Distribution of Gallium in Silicon Crystals for Photovoltaic Applications", Jpn. J. Appl. Phys. 46 (2007) 2831.

[2] T. Schutz-Kuchly, J. Veirman, S. Dubois and D. R. Heslinga, "Light-induced-degradation effects in boronphosphorus compensated n-type Czochralski silicon", Applied Physics Letters 96(9) (2010) 093505.

[3] J. Schmidt, K. Bothe and R. Hezel, "Oxygen-related minority-carrier trapping centers in p-type Czochralski silicon", Applied Physics Letters 80(23) (2002) 4395.

[4] B. Lim, S. Hermann, K. Bothe, J. Schmidt and R. Brendel, "Solar cells on low-resistivity boron-doped Czochralski-grown silicon with stabilized efficiencies of 20 \%”, Applied Physics Letters 93(16) (2008) 162102.

[ 5 ] S.W. Glunz, S. Rein, J.Y. Lee and W. Warta, "Minority carrier lifetime degradation in boron-doped Czochralski silicon”, J. Applied Physics 90(5) (2001) 2397.

[6] J. Schmidt and A. Cuevas, "Electronic properties of lightinduced recombination centers in boron-doped Czochralski silicon", J. Applied Physics 86(6) (1999) 3175.

[ 7 ] S.W. Glunz, S. Rein, W. Warta, J. Knobloch and W. Wettling, "Degradation of carrier lifetime in $\mathrm{Cz}$ silicon solar cells", Sol. Energy Mater. Sol. Cells 65 (2001) 219.

[ 8 ] H.J. Moller, C. Funke, M. Rinio and S. Scholz, "Multicrystalline silicon for solar cells", Thin Solid Films 487 (2005) 179.

[9] R.M. Swanson, "A vision for crystalline silicon photovoltaics", Progress in Photovoltaics: Research and Applications 14 (2006) 443.

[10] T.M. Bruton, "General trends about photovoltaics based on crystalline silicon", Solar Energy Materials and Solar Cells 72 (2002) 3.

[11] K.H. Lee, "A study on the surface characteristics of diamond wire-sawn silicon wafer for photovoltaic application”, J. Korean Crystal Growth and Crystal Technology 21(6) (2011) 225.

[12] T. Hoshikawa, T. Taishi, S. Oishi and K. Hoshikawa, "Investigation of methods for doping $\mathrm{CZ}$ silicon with gallium”, J. Crystal Growth 275 (2005) e2141.

[13] Y.-H. Kim, H.-Y. Chung, H.-Y. Cho, B.-Y. Lee and H.-D. Yoo, "Determination of metal impurities at near surface of silicon wafer by etching method", J. Korean Chem. Soc. 44 (2000) 200. 